\title{
Color Blindness (Color Vision Deficiency- Daltonism)
}

\author{
Ana Cristina Selvi Daniel* \\ Ophthalmologist, São Paulo, Brazil
}

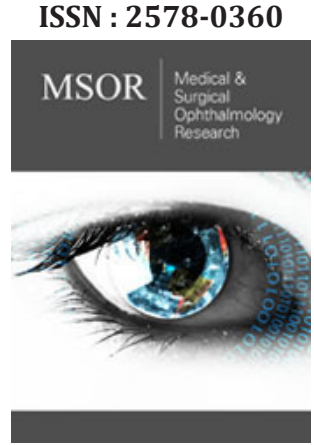

*Corresponding author: Ana Cristina Selvi Daniel, Ophthalmologist, São Paulo, Brazil

Submission:

Published: 址 November 06, 2020

Volume 3 - Issue 1

How to cite this article: Ana Cristina Selvi Daniel. Color Blindness (Color Vision Deficiency-Daltonism). Med Surg Ophthal Res. 3(1). MSOR. 000551. 2020.

DOI: 10.31031/MSOR.2020.03.000551

Copyright@ Ana Cristina Selvi Daniel, This article is distributed under the terms of the Creative Commons Attribution 4.0 International License, which permits unrestricted use and redistribution provided that the original author and source are credited.

\section{Opinion}

Color Blindness is the decreased ability to see colors or differences in color and may make some educational activities more difficult. However, problems are generally minor, and most color-blind people adapt. People with total color blindness (Achromatopsia) may also be uncomfortable in bright environments and have decreased visual acuity. Color Blindness is typically an inherited genetic disorder most commonly X-linked recessive inheritance. This means that a woman who cares this gene has $50 \%$ possibility to transmit to his son and, if she has the illness, $100 \%$ possibility to transmit. In almost all cases people retain blueyellow discrimination, and most color-blind individuals are anomalous trichromats rather than complete dichromats (they often confuse red and green items).

\section{Classification}

Monochromacy as known as "total color blindness" (Rod or Cone Monochromacy). Dichromacy- Protanopia (absence of red retinal photoreceptors) difficulties distinguishing between blue and green colors and red and green colors. 1\% of males are affected. Deuteranopia-affects hue discrimination in similar way to protanopia. $1 \%$ of males are affected. Tritanopia-only red and green pigments are present with a total absence of blue retinal receptors, rare situation. Anomalous trichromacy is a common type of inherited color vision deficiency. Protanomaly-mild color vision defect with altered spectral sensitivity of red retinal receptors. Hereditary sex-linked (1\% of males). Deuteranomaly-altered green retinal receptors: Most common type affecting red-green hue discrimination in 5\% European males. Hereditary sex-linked.

Tritanomaly-affects blue-green and yellow-red/pink hue discrimination. Some of the inherited diseases known to cause blindness are

a. Cone dystrophy

b.Cone-rod dystrophy

c. Achromatopsia

d. Blue cone monochromatism

e. Leber's congenital amaurosis

f. Retinitis pigmentosa

\section{Diagnosis}

Sometimes is difficult to diagnose specially when we have a mild color blindness. In serious type swe can find visual chromatic tests as Ishihara and Farnsworth 100 Hue. These tests can be done in pre-school students but is easier to evaluate in students with 10 years old and more. Most clinical tests are designed to be fast, simple, and effective at identifying 
broad categories of color blindness. Electroretinography-Evaluate the retinal function by capturing the electrical activity on light stimulation. There is no cure for color deficiencies. But they can use lenses increasing the contrast between colors enhancing the chromatic discrimination. Many mobile and computer apps have been developed to help color blind individual to view better. Color blindness may make it difficult or impossible for a person to engage in certain occupations. A Brazilian court ruled that people with color blindness are protected by Inter-American Convention on the Elimination of all Forms of Discrimination against Person with Disabilities.

\section{Conclusion}

It is important to monitoring the child and observe her behavior when the same cannot answer correctly about colors. Also, important to do an ophthalmological control since pre-school ages. By age 5 children with normal color vision can identify all of groups of colors in a couple of seconds. 